\title{
The Attribution Theory of Confucianism and Its Function To Mental Health
}

\author{
Jun Wang ${ }^{1^{*}}$ Jipeng Li, Rensheng Han, Yongjun Dan ${ }^{2}$ \\ ${ }^{1}$ Office of Students' affairs, Qufu Normal University, No. 57, Jingxuan West Rd, Qufu, Shandong, 273165, P. R. \\ China ${ }^{2}$ School of Educational Science, Qufu Normal University, No. 57, Jingxuan West Rd, Qufu, Shandong, \\ 273165, P. R. China
}

\begin{abstract}
This paper explores the attribution theory of Confucianism, which consists of two aspects: first, faced with major life mishaps, such as sickness or death, Confucianism intends to attribute them to external factors of "Tianming", unstable, uncontrollable fate; second, meeting failures or frustrations in enterprise pursuits, they usually attribute them to internal, stable and controllable factors. Referring to the modern attribution theories, such views of attribution may have some positive role on people's enterprises and life. More studies are needed to examine the impacts the theory on people's psychology and behaviors.
\end{abstract}

Keywords causal attribution, attribution theory, Confucian culture, mental health

\section{INTRODUCTION ON ATTRIBUTION THEORY RESEARCH}

The five thousand years of Chinese civilization are like a long opera, one dynasty replacing another constantly, emperors coming and going, peace following chaos. People hoped to know the causes of events, answer the questions in their minds, explored the mysteries of historical cycles. Broadly spoken, this is called "attribution". "That which is done without man's doing is from Heaven. That which happens without man's causing is from the ordinance of Heaven" (The Works of Mencius). This is often called "Tianming", which are translated as destiny of God/Heaven (Raphals, 2003), or "meant to happen" (Norenzayan\& Lee, 2010). Confucian wisdom tells us to understand destiny or fate, and strive to achieve the ideal. This reflects the unique attribution theory of Confucian culture.

Attribution means searching for the possible cause for the result, and is a kind of social cognitive process. To be specific, it means individuals infer the cause of the result by the interior disposal of information, such as perception, thoughts, and so on, according to the outcome of the action or the event.

The attribution theory has been one of the important research projects of psychology. In 1958, Heider (1958) started a new chapter for attribution theory. His book named The Psychology of Interpersonal Relations enjoyed great popularity. In the light of his attribution theory, the causes were divided into internal cause and external cause, so it was called two-dimensional attribution theory. While the internal cause consisted of motivation, emotion, affection, attitudes, the external causes included environment, the nature of the work, rewards and punishments, etc. The exposition of Jones and Davis on the question $(1965,1976)$ was known as Correspondent Inference Theory, according to this which, people needed to judge whether the action was intentional or not in making inferences. Furthermore, Kelly (1973) proposed the attribution model of variance analysis in which the cause is divided into three aspects: person, context and stimulus. All these theories focused on the cognitive process, and how people used inside information to make attribution.

Different from the theoretical perspectives above, Weiner $(1970,1972)$ not only realized the effect of attribution in the motivation, emotion and behavior, but also constructed a complete framework of motivation and emotion with the "attribution" at the core. The cause was divided into three dimensions: locus, stability, controllability, each dimension could be partitioned to dichotomous, internal to external, stability to instability, and controllability to uncontrollability. Therefore, it was named as three-dimensional model. Furthermore, Bandura (1977) advanced the self-efficacy theory, illustrating people's perception or belief of effective control of themselves. And Seligman (1978) proposed the learned helplessness theory, in his view, the reasons for behavior was not negative life events, but a feeling of helplessness.

According to Weiner's theory, Individual's achievement motivation causes can be divided into four categories: ability, effort, luck and the difficulty of task (Weiner, 2000). The first two items were classified as internal attribution, the last two items as external attribution. On the other hand, Attribution style can be divided into positive and negative attribution styles. The positive attribution style refers to attribute negative life events to external, instability and uncontrollable causes. To attribute failures to lack of effort is considered as a positive attribution style. So, when faced with failures or frustrations in enterprise pursuits, a good and wise man is 
convinced that he is not working hard enough, which is a positive attitude, and could reinforce the belief that success comes when work hard. The attribution theory reflects the link of people's inner cognitive system and behaviors. This is an incredibly dynamic force that shapes behaviors. A good and wise man changes his attribution style, and then has strong incentive to achieve a goal.

In recent years, the research on attribution theory has been made considerable advances. For example: Rempel, Ross\& Holmes (2001) examined the relationships between trust and communicated Attributions in romantic relations. Based on Heider's theory, a wider range of social perception theories was proposed by Crandall, Silvia, N'Gbala and Dawson (2007). On the other hand, Lanctôt, Bergeron-Brossard, Sanquirgo and Corbière (2013) explored the attribution style of unemployed people with mental disorders, under the guidance of the Weiner's frameworks. In addition, the cognitive attributions of depression have been extensively studied (Rubenstein, Freed, Shapero, Fauber \& Alloy,2016).

The attribution theory began to spread into China in the late 1980s, and related studies were emerging in an endless stream thereafter. Researchers have tried to make use of its principles and methods directly and to explain and predict the behaviors and received conspicuous achievements in many fields: educational, sports, career strategy, and clinical applications. Among them education is one of the most important research application fields in attribution theory, and has made a striking achievement. It can be applied generally into five fields : (1) practical application in teaching;(2) impact on education; (3) directing students to form a right attrition; (4)improving the unsuitable attribution style for girls; (5) attribution training (Han,2004).Attribution training in sports context can was helpful to form cognitive schema, and transferred into academic attribution (Luo,2007).Some scholars examined the moderating roles of locus of control in the relationship between economic confidence and career decision making self-efficacy (Kuang, Zheng, Lin, Yang \& Liu,2011), Low explanatory flexibility may be associated with higher levels of depression and anxiety, but lower positive mood and optimism.(Zhen-Hua, Chen,\& Jiang, 2012).

Inevitably, cultures have a huge impact on people's attributive cognition (Norenzayan, \& Heine2005; Heine \& Norenzayan, 2006). On this regard, some scholars studied the influence of collectivism and individualism (Tata\& Leong, 1994; Oyserman\& Lee,2008; Oyserman, Sorensen, Reber \& Chen, 2009). And some focuses on self-serving attributional bias (Mezulis, Abramson, Hyde\& Hankin, 2004). In the past few decades, people paid more and more attentions to the relationship between the culture and attribution theory (Chiu, Morris, Hong\& Menon,2000; Peng\& Knowles,2003). The study by Peng and Wong (1997) showed that Chinese were more likely to explain it from the angle of environment on fuzzy physical events. The connotation of attribution theory could not be used equally in all cultures.(An\& Trafimow,2013). So we need to sort out classical books and assailed the attribution theory of Chinese traditional culture.

\section{CONFUCIAN PHILOSOPHY AND THE COGNITION OF ATTRIBUTION}

Confucius and his disciples elaborated the school of thoughts at the end of Spring and Autumn period. And their perspectives were interpreted in five classics: the Book of Songs, the Book of History, the Book of Changes, the Book of Rites and the Spring and Autumn Annals; their main ideas included: Confucius was regarded as the teacher; His actions were treated as the highest standards; advocating benevolence and righteousness; and maintaining Confucian rules and ethics. Confucianism became the dominant ideological trends in the Western Han Dynasty (Fan Wenlan.1975), which had a far-reaching influence on the development of the Chinese society and cultures later on. The ideal of the Confucianism was to educate people with high ethical standards, whom we call "Junzi", it always was translated as gentleman or "exemplary or paradigmatic person" (Tan, 2015). Initially, the "Junzi" referred to the rulers and noble man, and then it evolved into the title of moral people. The concept of "Xiaoren" generally refers to people with low status as opposed to "Junzi" (Yang, 2013).

Confucian cultures covered the systematic theories and codes of ethics, which provided materials and basis for the development of Chinese psychology and personality (Huang \& Charter, 1996). Its rules of benevolence, justice, ceremony, wisdom, and credibility provided guidance and standards for people's behaviors. The teaching built the ideal personalities of a gentleman, at the same time constructed the personality of the ordinary people (Luo \& Huang, 2010), which also affect the attribution style of the individual.

Confucian cultures taught people the idea of success and positive attitudes to life. "The ancients, who wished to illustrate illustrious virtue throughout the kingdom, first ordered well their own States. Wishing to order well their States, they first regulated their families. Wishing to regulate their families, they first cultivated their persons. Wishing to cultivate their persons, they first rectified their hearts" (The Great Learning). The gentleman's attitude to life provides an example for the people and urged people to achieve the dream. "The man of honor will strive constantly for self-improvement"(The Book of Changes). Yet the road to become a "Junzi" is long and bumpy, so it is important to view their own and others' behaviors and to make attributions for these behaviors. 


\section{MEANINGS AND CHARACTERISTICS OF CONFUCIAN ATTRIBUTION THEORY}

Confucian perspectives on attribution encompassed two major aspects: on the one hand, faced with major life mishaps, such as sickness or death, the Confucianism intends to attribute to external factors of "Tianming", unstable, uncontrollable fate. For example: "There is the following saying which I have heard: Death and life have their determined appointment; riches and honors depend upon Heaven. Let the superior man never fail reverentially to order his own conduct, and let him be respectful to others and observant of propriety" (The Analects of Confucius p.187). Sze-ma Niu was deeply troubled because he hasn't got any brothers. He was consoled by the fact that this is destiny. However, to strengthen their self-cultivation would bring him more friends. When Confucius first heard the news of the death of his disciple, the favorite Yen Hui, he cried out in an outburst of grief, "Oh! Oh! God has forsaken me! God has forsaken me!” (The Analects of Confucius p.167)

Confucius was deeply grieved by his death. It liked that God wants to kill Confucius. Eventually Confucius could only attribute it to external factors "Tianming". Similar to this, another disciple was ill, Confucius also attributed it to fate. Po-niu being ill, the Master went to ask for him. He took hold of his hand through the window, and said, "It is killing him. It is the appointment of Heaven, alas!" (The Analects of Confucius p.81) "If Heaven had wished to let this cause of truth perish, then I, a future mortal! Should not have got such a relation to that cause, While Heaven does not let the cause of truth perish, what can the people of this place do to me?" (The Analects of Confucius p.131)

When Confucius was up the creek, and suffered the situation that was far from the change by people, Confucius attributed it to Heaven. And it was also recorded by Chuang-tzu in his writings. "I have not been willing to admit failure for a long time, but in vain. Fate is against me. I have been seeking success for a long time, but in vain. The hour has not come" (Chuang Tse). Based on these words, we can conclude that Confucius attributed it to fate or heaven. The Master said, "Heaven produced the virtue that is in me. What can he do to me?" (The Analects of Confucius). On one occasion of great personal danger to his person from an enemy, Confucius escaped unharmed. He believed that God helped him.

In the Confucian Culture, "Tianming" intended to work on many levels. Yang (1958) proposed that "Tian" have three meanings: sky, fate or destiny, ethics and morals. "Ming" has some meanings such as life, fortune and mission. This article only tries to discuss the "the fate or destiny" and "fortune". Confucian view of "Tianming" was not a real sense of fatalism. It not only emphasizes the master of destiny; more emphasis was put on one's own efforts. Confucius remarked, I do not repine against God, nor do I complain of men. My studies are among lowly things; but my thoughts penetrate the sublime. Ah! There is perhaps only God who understands me (The Analects of Confucius). Confucius taught disciples should not complain, tried their best to learn knowledge, and waited for better luck. This teaching advocated that a firm belief could overcome many difficulties and give people the confidence in the face of adversity for the future, and then succeed in life.

So, how did a good and wise man treat fate or destiny? Confucius remarked, "Without recognizing the ordinances of Heaven, it is impossible to be a superior man" (The Analects of Confucius). Confucius gave his advises that if someone wanted to be a good and intelligent man, one of the most important things was that he should be acquainted with the principle of God. Confucius remarked, "There are three things which a wise and good man holds in awe. He holds in awe the Laws of God, persons in authority, and wisdom of holy man" (The Analects of Confucius). Confucianism believes that the one that shapes destiny will always be supernatural being, we should respect it. We may say therefore that he who is greatly virtuous will be sure to receive the appointment of Heaven (The Doctrine of the Mean). Failure and setbacks are temporary, as long as you have the patience to wait and the courage to improve yourself.

There is another aspect of Confucian attribution theory: faced with failures or frustrations in enterprise pursuit, they usually attribute to internal, stable and controllable factors. Mencius said, "When we do not, by what we do, realize what we desire, we must turn inwards, and examine ourselves in every point" (The works of Mencius). Generally, it is easy to judge the mistakes of others, but it is difficult to recognize one's own defects. If you cannot win their respect when you treat others honestly, then you need to reflect regret your faults. The Master said, "In archery we have something like the way of the superior man. When the archer misses the center of the target, he turns round and seeks for the cause of his failure in himself" (The Doctrine of the Mean). Similarly, we should deal with failures with an ordinary attitude. "a wise and good man should be distressed that he has no ability; he should never be distressed that men do not take notice of him; a wise man seeks for what he wants in himself, a fool seeks for it from others; the same disciple remarked, a fool always has an excuse ready when he does wrong" (The Analects of Confucius p.257).

A good and wise man think that failure is caused by internal, stable and controllable causes. In contrast, the people in low position believe that it is due to external, unstable and uncontrollable causes. This is apparently not advocated by Confucianism. In addition to achievement motivation attribution, interpersonal attribution also can be found in the classical of Confucianism. Confucius remarked, "A man who excepts much 
from himself and demands little from others will never have any enemies" (The Analects of Confucius). If a good and wise man has the courage to take the blame, then he tends to have friends and supportive relationships.

In summary, the attribution theory of Confucian perspective consists of two major aspects: first, faced with major life mishaps, such as sickness or death, it intends to attribute to external factors of "Tianming", unstable, uncontrollable fate; second, faced with failures or frustrations in enterprise pursuit, they usually attribute them to internal, stable and controllable factors. Hence, people are taught not only to prepare for success, but also have the courage to stand up to setbacks.

\section{DEVELOPMENT OF FATE ATTRIBUTION}

The same psychological phenomenon has universality and differences in different cultural backgrounds (Norenzayan \& Heine, 2005). As an old Chinese saying goes, "The planning lies with man, the outcome with Heaven." The west has the same proverb: "Man proposes, God disposes" When meeting any difficulties in China, people always seek aid of Heaven. Similar to this, people always pray for God blessing in face of difficulties in west. And they think that meeting important and inevitable things was the arrangement of the fate (Norenzayan\& Lee, 2010). Norenzayan and Lee (2010) conclude that ethnic culture and religious affiliation have a significantly influence on fate attribution. East Asian Canadians and Christian are more likely to make fate attribution that often bound up with religious attribution. When people are unable to explain why it happened, they always attributed it to God or Satan (Ritzema\& Young, 1983; Lupfer, Tolliver, \& Jackson, 1996). That is similar with Confucius's point of view, "Confucius always refused to talk of supernatural phenomena; of extraordinary feats of strength; of crime of unnatural depravity of men; or of supernatural beings" (The Analects of Confucius). Confucius enjoys a high reputation for rigorous scholarship; he regards some things as the mandate of heaven, probably because people cannot explain why it happened.

The research by Pargament et al. (1988) found that there are basically three forms of the ways of God works: self-directing style, deferring style and collaborative style. Confucianism revered the God's will, but they did not have a blind faith in it. "Do one's level best and leave the rest to God's will", thus it can be seen that fate and individual in a cooperative relationship. A gentleman can be a winner and realize the lofty ideal only by improving their own moral qualities when meeting a good fate.

Studies have found that when the negative life events bring a positive long-term result, people are more likely to attribute it to God and less likely to attribute it to Satan. People who believe God is rescuer and comforter (Ray, Lockman, Jones \& Kelly, 2015). The view on this point is similar to Confucianism. When Heaven is going to give a great responsibility to someone, it first makes his mind endure suffering. It makes his sinews and bones experience toil, and his body to suffer hunger. It inflicts him with poverty and knocks down everything he tries to build (The Works of Mencius). The life with a lot of disappointments and setbacks. The trouble of life will temper your willpower. They are best helper for steeling will.

Compared to the daily life, people intended to attribute to God when facing with life-altering events (Lupfer, \& Layman, 1996). Baker (2008) suggests that women and African Americans are more likely to attribute to hell, devil and Satan, and people with high education level and high income are less likely to attribute to these factors. Beck and Taylor (2008) think that this attribution mode plays an important role in the happiness of the spirit of Christianity. In China, people have a tradition of divination and doing the sacrifice of heaven. Confucius remarked, "I have not been able to find a flaw in the character of an ancient emperor, the Great Yu. He was extremely simple in his own food and drink, but lavish in what he offered in sacrifice. His ordinary clothing was coarse and poor, but when he went to worship he appeared in rich and appropriate robes" (The Analects of Confucius p.124). So we think that the sacrifice to the heaven may affect fate attribution.

In conclusion, we can assume that gender, education level, income status, ethnic cultural, religious affiliation, divination and long-term results are likely to affect fate attribution. It pointed out the direction for our future research. But beyond that, we should not neglect the influence of fate attribution on mental health, which also requires further research.

\section{THE IMPACT OF CONFUCIAN ATTRIBUTION THEORY ON PSYCHOLOGY AND BEHAVIORS}

Emotion was related to perceived locus of cause and controllability, expectation was connected to perceived stability of cause, motivation and behaviors were linked to emotion and expectation (Forsyth\& McMillan, 1981; Weiner, 1985). When confronted with major life mishaps, such as sickness or death, the Confucianism intends to attribute to external factors of "Tianming", which helps people keep expectations for the future and avoid the negative emotions. The conception of "self-cultivation, family harmony, country management and world peace" is in tune with the desire for success. A student who has exceptional abilities, more than sufficient to carry on his studies, should enter the public service (The Analects of Confucius). Under the influences of Confucianism, individuals have high expectations for the future; this is helpful to realize the aspiration of illustrating virtues throughout the kingdom. 
The mental health level is affected by many factors. Studies have reported that culture has an important influence on mental health (Cauce, Domenech-Rodríguez, Paradise. etal, 2002; Cross, 2003). Jing (2007) found that Confucian culture contributes to psychological counseling with some aspects, such as significance of life, coping style and so on. Jing (2006) also projected that Confucian coping is beneficial to mental health. The optimism propounded by Confucianism is an idealistic one that advocates rationality, involvement in society, and getting pleasure in life (Huo, Chen, \& Guo, 2013).

The viewpoint of "Tianming" in Confucianism may be beneficial to the physical and mental health. When faced with setbacks failure, there are a lot of people who feel frustrated and have to explain and speculate their conducts. Then these feelings will affect the motivation, which in turn result in different attitudes and behaviors. New behaviors constantly beget new attributions. When Confucius visited K'uang, the men of Sung surrounded him by several cordons. Yet he went on singing to his guitar without stop (Chuang Tse). Confucius thought it was fate that he encountered danger. Therefore, he didn't get frustrated. While the luck was in, the good and wise man can obtain the success. If, by ill-luck, people need to study hard and strengthen education.Confucius remarked, "A wise and good man is composed and happy, a fool is always worried and full of distress."; "Men of intelligence are free from doubts, moral men free from anxiety, and men of courage from fear."; "A good and wise man is without anxiety and without fear" (The Analects of Confucius p.112).

So, the great person usually has a great mentality. To summarize, the attitude to frankly face difficulties and not to complain is a very high level. The attribution theory of Confucian culture can help people to maintain a positive attitude at all times. Through continuous efforts, a good and wise man resolves inner conflicts, and meets the change and developments of social environment as soon as possible.

Confucius is the greatest philosopher in Chinese history. He connected the virtue to gentleman. To become a gentleman has been an ideal objective of personality for most people. The nucleus of Confucian thoughts is the idea of "humanity" or "love", and the executive of this subject is the gentlemen. They have good morals to cultivate, hold lofty ideal, value the spirit of self-reliance and perseverance and be self-regulating. The ideal of becoming a gentleman is considered viable for most people and an achievable goal. Although not anyone can become a gentleman, we hope that each of us can follow what Sima Qian advocated, "Though unachievable, aspiration to it remains."

The Confucian cultures are accumulated with the constant development of society and ethnic groups. This paper is a preliminary examination of the key contents of Confucian attribution theory. There is a lot of room for improvement. In addition, empirical studies are needed to test its impacts on people's psychology and behaviors. With the development of the economy, old Confucian ideas are gaining the new content which enables people to express their thoughts and tackle with on major changes.

\section{REFERENCES}

[1] Abramson, L. Y., Seligman, M. E., \& Teasdale, J. D. (1978).Learned helplessness in humans: Critique and reformulation. Journal of Abnormal Psychology, 87(1), 49-74.

[2] An, S., \& Trafimow, D. (2013). Affect and morality: a cross-cultural examination of moral attribution. Journal of Cross-Cultural Psychology, 45(3), 417-430.

[3] Baker, J. (2008). Who believes in religious evil? An investigation of sociological patterns of belief in Satan, Hell, and Demons. Review of Religious Research, 50(2), 206-220.

[4] Bandura, A. (1977). Self-efficacy: Toward a unifying theory of behavioral change. Psychological Review, 84(2), 191-215.

[5] Beck, R., \& Taylor, S. (2008). The emotional burden of monotheism: Satan, theodicy, and relationship with god. Journal of Psychology \& Theology, 36(3), 151-160.

[6] Cauce, A. M., Domenech-Rodríguez, M., Paradise, M., Cochran, B. N., Shea, J. M., Srebnik, D., \& Baydar, N. (2002).Cultural and contextual influences in mental health help seeking: A focus on ethnic minority youth. Journal of Consulting and Clinical Psychology, 70(1), 44-55.

[7] Chiu, C., Morris, M. W., Hong, Y., \& Menon, T. (2000).Motivated cultural cognition: The impact of implicit cultural theories on dispositional attribution varies as a function of need for closure. Journal of Personality and Social Psychology, 78(2), 247-259.

[8] Crandall, C. S., Silvia, P. J., N'Gbala, A. N., Tsang, J., \& Dawson, K. (2007). Balance theory, unit relations, and attribution: The underlying integrity of Heiderian theory. Review of General Psychology, 11(1), 12-30.

[9] Cross, T. L. (2003). Culture as a resource for mental health. Cultural Diversity and Ethnic Minority Psychology, 9(4), 354-359.

[10] Fan, W. L. (1975). Confucius and the Confucian theories he created. Chinese Law \& Government, 8(4), 11-22.

[11] Forsyth, D. R., \& McMillan, J. H. (1981). Attributions, affect, and expectations: A test of Weiner's threedimensional model. Journal of Educational Psychology, 73(3), 393-403. 
[12] Gu, H.M. trans.(2011).The Analects of Confucius. Kunming, the Peoples Press of Yunnan.

[13] Han, R. S. (2004). Return-\&-cause theory in education. Theory \& Practice of Education, 24(2), 4-7.

[14] Heider, F. (1958).The Psychology of interpersonal relations. New York, NY: Wiley.

[15] Heine, S. J., \& Norenzayan, A. (2006).Toward a psychological science for a cultural species. Perspectives on Psychological Science, 1(3), 251-269.

[16] Huang, D. D., \& Charter, R. A. (1996). The origin and formulation of Chinese character: An introduction to Confucianism and its influence on Chinese behavior patterns. Cultural Diversity and Mental Health, 2(1), 35-42.

[17] Huo, Y., Chen, Y., \& Guo, Z. (2013).An exploration on the Inter complementary optimistic psychological thoughts of the Confucianism and Taoism in the traditional Chinese culture. Acta Psychologica Sinica, 45(11), 1305-1312.

[18] Jing, H. B. (2006).Confucian coping and its role to mental health. Acta Psychologica Sinica, 38(1), 126134.

[19] Jing, H. B. (2007). What Confucianism can contribute to psychological counseling? Acta Psychological Sonica, 39(2), 371-380.

[20] Jones, E. E., \& Davis, K. E. (1965). From acts to dispositions the attribution process in person perception 1. Advances in Experimental Social Psychology, 2(4), 219-266.

[21] Jones, E. E. (1976). How do people perceive the causes of behavior? Experiments based on attribution theory offer some insights into how actors and observers differ in viewing the causal structure of their social world. American Scientist, 64(3), 300-305.

[22] Kelley, H. H. (1973).The processes of causal attribution. American Psychologist, 28(2), 107-128.

[23] Kuang, L., Zheng, W. W., Lin, C. D., Yang, M., \& Liu, L. (2011). The relationship between economic confidence and career decision making self-efficacy of college students: the moderator effects of attribution and proactive personality. Acta Psychologica Sinica, 43(9), 1063-1074.

[24] Lanctôt, N., Bergeron-Brossard, P., Sanquirgo, N., \& Corbière, M. (2013).Causal attributions of job loss among people with psychiatric disabilities. Psychiatric Rehabilitation Journal, 36(3), 146-152.

[25] Leung, J. T. Y., \& Shek, D. T. L. (2014).Parental attributions of children's success and failure and family processes in poor Chinese families. Journal of Child \& Family Studies, 24(8), 1-13.

[26] Luo, M. C., \& Huang, X. T. (2010). The impact of the Confucian culture to present mental health services of Chinese. Advances in Psychological Science, 18(09), 1481-1488.

[27] Luo, X. L. (2007). A study of effect of sports attribution training context-crossed. Journal of Beijing Sport University, 30(10), 1434-1438.

[28] Lupfer, M. B., \& Layman, E. (1996).Invoking naturalistic and religious attributions: A case of applying the availability heuristic? The representativeness heuristic? Social Cognition, 14(1), 55-76.

[29] [29] Lupfer, M. B., Tolliver, D., \& Jackson, M. (1996).Explaining life-Altering occurrences: A test of the 'God-of-the-Gaps' hypothesis. Journal for the Scientific Study of Religion, 35(4), 379-391.

[30] Mezulis, A. H., Abramson, L. Y., Hyde, J. S., \& Hankin, B. L. (2004).Is there a universal positivity bias in attributions ?A meta-analytic review of individual, developmental, and cultural differences in the selfServing attributional bias. Psychological Bulletin, 130(5), 711-747.

[31] Norenzayan, A., \& Heine, S. J. (2005). Psychological universals: What are they and how can we know? Psychological Bulletin, 131(5), 763-784.

[32] Norenzayan, A., \& Lee, A. (2010).It was meant to happen: Explaining cultural variations in fate attributions. Journal of Personality and Social Psychology, 98(5), 702-720.

[33] Oyserman, D. \& Lee, S. S. (2008).Does culture influences what and how we think? Effects of priming individualism and collectivism. Psychological Bulletin, 134(2), 311-342.

[34] Oyserman, D., Sorensen, N., Reber, R., \& Chen, S. X. (2009). Connecting and separating mind-sets: Culture as situated cognition. Journal of Personality and Social Psychology, 97(2), 217-235.

[35] Pargament, K. I., Kennell, J., Hathaway, W., Grevengoed, N., Newman, J., \& Jones, W. (1988). Religion and the problem-solving process: Three styles of coping. Journal for the Scientific Study of Religion, 27(1), 90-104.

[36] Peng, K., Nisbett, R. E., \& Wong, N. C. (1997).Validity problems comparing values across cultures and possible solutions. Psychological Methods, 2(4), 329-344.

[37] Peng, K., \& Knowles, E. D. (2003). Culture, education, and the attribution of physical causality. Personality \& Social Psychology Bulletin, 29(10), 1272-84.

[38] Raphals, L. (2003). Fate, fortune, chance, and luck in Chinese and Greek: a comparative semantic history. Philosophy East and West, 53(4), 537-574.

[39] Ray, S. D., Lockman, J. D., Jones, E. J., \& Kelly, M. H. (2015).Attributions to God and Satan about lifealtering events. Psychology of Religion and Spirituality, 7(1), 60-69. 
[40] Rempel, J. K., Ross, M., \& Holmes, J. G. (2001). Trust and communicated attributions in close relationships. Journal of Personality and Social Psychology, 81(1), 57-64.

[41] Ritzema, R. J., \& Young, C. (1983). Causal Schemata and the Attribution of Supernatural Causality. Journal of Psychology and Theology, 11(1), 36-43.

[42] Rubenstein, L. M., Freed, R. D., Shapero, B. G., Fauber, R. L., \& Alloy, L. B. (2016). Cognitive attributions in depression: bridging the gap between research and clinical practice. Journal of Psychotherapy Integration, http://dx.doi.org/ 10.1037/int0000030

[43] Tan, C. (2015). Understanding creativity in East Asia: insights from Confucius' concept of junzi. International Journal of Design Creativity \& Innovation, 4(1), 1-11.

[44] Tata, S. P., \& Leong, F. L. (1994).Individualism-collectivism, social-network orientation, and acculturation as predictors of attitudes toward seeking professional psychological help among Chinese Americans .Journal of Counseling Psychology, 41(3), 280-287.

[45] ]Weiner, B., \& Kukla, A. (1970).An attributional analysis of achievement motivation. Journal of Personality and Social Psychology, 15(1), 1-20.

[46] Weiner, B. (1972). Theories of motivation: From mechanism to cognition. Chicago: Markham.

[47] Weiner, B. (1985).An attributional theory of achievement motivation and emotion. Psychological Review, 92(4), 548-573.

[48] Weiner, B. (2000).Intrapersonal and interpersonal theories of motivation from an attributional perspective. Educational Psychology Review, 12(1), 1-14.

[49] Weiner, B. (2008). Reflections on the history of attribution theory and research: People, personalities, publications, problems. Social Psychology, 39(3), 151-156.

[50] Yang, B. J. (1958).The interpretation of Analects of Confucius. Beijing, the Chinese Publishing House.

[51] [51] Yang, C. (2013).The "method" of being a man and the "virtues" of administrating. Theory Journal, $11,95-101$

[52] Zhen-Hua, Q. I., Chen, J., \& Jiang, H. (2012).Relation of attribution styles and attribution flexibility to mental health in college students. Chinese Mental Health Journal, 26(4), 310-314. 